\title{
Fugitive methane and odour emission characterization at a composting plant using remote sensing measurements
}

\author{
Vesenmaier A. ${ }^{1}$, Reiser M. ${ }^{1 *}$, Zarra T. ${ }^{2}$, Naddeo V. ${ }^{2}$, Belgiorno V. ${ }^{2}$ and Kranert M. ${ }^{1}$ \\ ${ }^{1}$ University of Stuttgart, Institute for Sanitary Engineering, Water Quality and Solid Waste Management, Bandtäle 2, 70569 Stuttgart, \\ Germany \\ 2Sanitary Environmental Engineering Division (SEED), Department of Civil Engineering, Università degli Studi di Salerno, via Giovanni \\ Paolo II, 132 - 84084 Fisciano (SA), Italy \\ Received: 22/06/2018, Accepted: 17/09/2018, Available online: 26/09/2018 \\ *to whom all correspondence should be addressed: e-mail: martin.reiser@iswa.uni-stuttgart.de \\ https://doi.org/10.30955/gnj.002802
}

\section{Abstract}

Gaseous emissions of biowaste treatment facilities have several adverse effects. In Germany, a law to collect biological waste separately was introduced in January 2015. Since then there is a discussion about greenhouse gases which could be emitted in a significant rate and exceed the positive aspects. Default factors for methane and nitrous oxide from biological treatments given by the Intergovernmental Panel on Climate Change (IPPC) suggests that fugitive emissions even from composting processes should not be neglected. The research work presents an innovative method to quantify fugitive methane and odour emissions at a composting plant. The proposed method uses a combination of a remote sensing measurements and the application of a backwards Lagrangian stochastic (bLs) based micrometeorological dispersion modelling. The remote sensing technology is based on the absorption of infrared light with a wavelength sensitive to the substance to be determined. With the downwind measured methane concentration deducted by the upwind measured background concentration and the known wind conditions, a gas dispersion is simulated back in time to estimate the gas emission rate of a plant. Using the methane emissions as a tracer for dispersion characteristics in the atmosphere it is even possible to estimate a more accurate odour emission rate from passive sources at composting plants.

Keywords: Composting, methane emissions, odour emissions, remote sensing, biowaste.

\section{Introduction}

In Germany the law on Life-Cycle Management prescribes that biological waste has to be collected separately at the latest from $1^{\text {st }}$ of January in 2015 (Kreislaufwirtschaftsgesetz - KrWG). In the regulation it is indicated that one of the main technologies for biowaste treatment is through the aerobic composting. The compost production benefits the preservation of resources and thus showing the importance of this type of treatment (Cadena et al., 2009). On the contrary the impact on climate change produced by the emitted greenhouse gases (GHG) and on the population surrounding the plants due to odour emissions might counteract the benefits (Zarra et al., 2009; Giuliani et al., 2012; Zarra et al., 2016; Zhu-Barker et al., 2017). The characterization and control of greenhouse gas and odour emissions in the composting process is crucial in order to reduce the impact on climate change and social aspects (Cadena et al., 2009). The most important GHG emitted by composting plants are methane $\left(\mathrm{CH}_{4}\right)$ and nitrous oxide $\left(\mathrm{N}_{2} \mathrm{O}\right)$.

Composting as an aerobic process is not intentionally linked to methane. During the composting process methane is formed in anaerobic sections of the material to be treated (Cassendra et al., 2017). Not all of the methane that is generated is then oxidized in the aerobic sections and a part is emitted into the atmosphere. Under unpropitious circumstances during substrate degradation the nitrification and denitrification, respectively are incomplete. Depending on oxygen availability and temperature distribution in the treated material this results in the formation of nitrous oxide (IPCC, 2006).

The Intergovernmental Panel on Climate Change published a guideline for national greenhouse gas inventories (IPCC, 2006). Emission factors are proposed for quantifying greenhouse gas emissions at biological treatment plants. Accordingly to the guideline the methane emission factor for composting of organic waste is generally between $30-8000 \mathrm{~g} \mathrm{CH}_{4} / \mathrm{Mg}$ input or given by a default value of $4000 \mathrm{~g} \mathrm{CH}_{4} / \mathrm{Mg}$ input. The nitrous oxide emission factor for composting is theoretically between $60-600 \mathrm{~g} \mathrm{~N}_{2} \mathrm{O} / \mathrm{Mg}$ input or given by a default value of $240 \mathrm{~g} \mathrm{~N} 2 \mathrm{O} / \mathrm{Mg}$ input.

Odour emissions in ambient air are complex to measure. During last decades several techniques were proposed for the measurement of odours in environmental field but until now no one was applied and diffused between worldwide countries (Zarra et al., 2014). Likewise, currently there is no reliable and generally accepted measurement method to quantify fugitive and total GHG 
emission rates at composting plants. Lately more and more literature emerges containing the quantification of methane emissions at agricultural biogas plants (Flesch et al., 2011; Groth et al., 2015; Hrad et al., 2015).

The use of a method, which has already been successfully used at agricultural biogas plants and at landfills seems to fit the requirements to quantify fugitive greenhouse gas and odour emissions of composting plants. As a side effect the odour emission rate can be estimated by this method using methane as a tracer.

In this study an innovative method has been applied to characterize and quantify the overall methane emission rates at a composting plant with the aim to evaluate the impact on climate change of composting plants. The proposed method uses a combination of remote sensing measurements and a micrometeorological dispersion modelling, and also allows estimating odour emissions.

\section{Materials and methods}

\subsection{Investigated plant and survey program}

The analyses were conducted at a composting plant located in the municipality of Baden-Wuerttemberg (Germany). The composting plant works in a windrow composting process of biowaste. The annual utilizing capacity is about $60000 \mathrm{Mg}$ of biowaste and green waste. All process stages are completely encapsulated. The exhaust air streams of the whole facility are collected and treated with wet scrubbers and biofilters. After the biofilters the collected exhaust air streams are actively released into the atmosphere by ventilated cooling modules.

Measurements took place in October 2015. On the one hand remote sensing measurements for fugitive methane quantification were performed. On the other hand online measurements of methane and nitrous oxide were performed with a Fourier transform infrared spectrometer (FTIR) on top of the biofilter as a collective emission source.

\subsection{Fugitive methane emissions characterization}

The proposed method combines a remote sensing measurement with micrometeorological dispersion modelling. Figure 1 shows graphically the procedural steps of the method and how they are merged together in order to provide an emission rate.

The emission rate is determined by tracking the gas dispersion from a downwind gas concentration backwards and taking the wind conditions into account.

In this study the methane concentrations were measured by tunable diode laser absorption spectroscopy (TDLAS). A spectrometer quantifies the concentration based on the absorption of infrared light at a specific wavelength for the gas species of interest. The absorption spectroscopy was performed by the GasFinder 2.0 (Boreal Laser Inc., NW) where the wavelength is adjusted to methane's absorption bands.

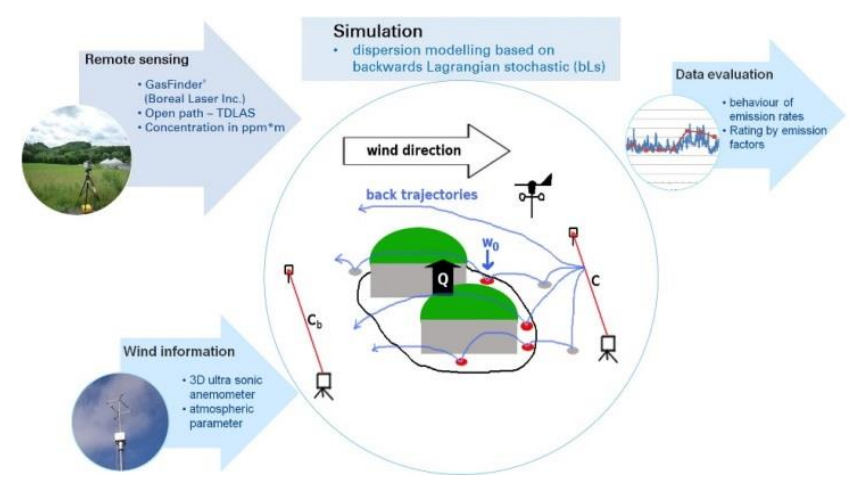

Figure 1. Schematic description of the proposed method

The spectrometer is transmitter and receiver at the same time. A line concentration is summed up along an open path between the light source and a retroreflector. This line concentration is given as a product of the path length and the average methane concentration in the unit "ppm $\times m$ ". Downwind the source the overall concentration of the area is measured (c). A second concentration measurement is set upwind the source $\left(c_{b}\right)$. In this way the background concentration is ascertained and the determination of the pure emissions from the examined source is guaranteed.

Wind information is very important in order to obtain the origin of the measured concentrations. The most important variables are wind direction and wind velocity. A three dimensional ultrasonic anemometer (uSonic-3 Scientific, METEK GmbH, D) also provides valuable atmospheric data. With that data the simulation of the emissions becomes even more realistic to the actual dispersion behaviour.

The dispersion modelling for this study was performed with the freeware WindTrax 2.0 (Thunder Beach Scientific, C). The model used in the software is based on a backwards Lagrangian stochastic (bLs). That means the emissions are tracked backwards over time in their dynamic dispersion in the atmosphere (Flesch et al., 2011). Therefore the measured concentration is interpreted as a particle. From various points placed evenly along the measuring line thousands of these particles are released. With some additional parameters describing the site properties back trajectories of the particles are simulated following the natural turbulent dispersion in the atmosphere. The intersections of the back trajectories with the surface are crucial, especially the ones which intersect with the source area.

Thereby every back trajectory has its own statistical possibility. With that possibility the model predicts a ratio of a downwind concentration to an emission rate $(C / Q)_{\text {sim. }}$. With this ratio and the measured concentration $C$ deducted by the background concentration $C_{b}$ the methane emission rate $Q$ of an examined source can be calculated with the following equation:

$$
Q=\frac{\left(C-C_{b}\right)}{(C / Q)_{\text {sim }}}
$$




\subsection{Odour emissions estimation}

Under certain conditions this quantification of fugitive methane emissions is also useful to calculate odour emission rates of passive odour sources. When methane and odours are emitted together from the same source, methane may be used as a tracer to determine the volume flow of the emissions. The schematic description of this odour emission estimation is given in Figure 2.

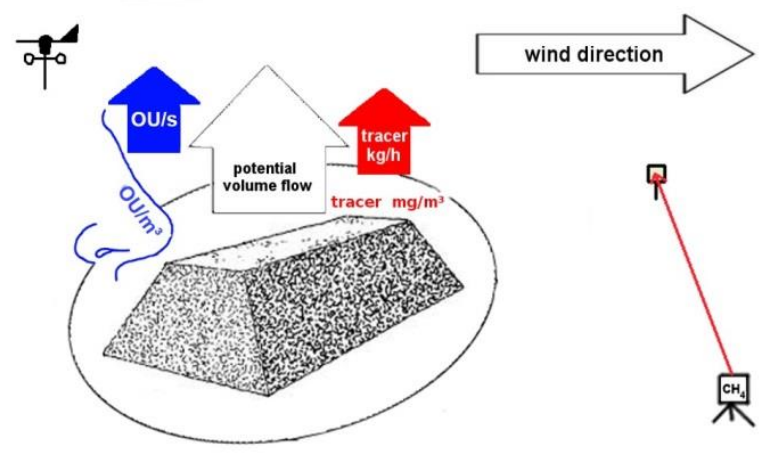

Figure 2. Odour emission estimation

Reverse dispersion modelling of the remote sensing methane concentrations delivers a methane emission rate $\mathrm{Q}_{\mathrm{CH} 4}$ of the observed source. Together with the onsite measured methane concentration $\mathrm{C}_{\mathrm{CH}} 4$ a potential volume flow $\dot{V}$ is assumed. With that potential volume flow and an actual onsite determined odour concentration codour an odour emission rate Qodour can be calculated as shown in the following equations:

$$
\begin{aligned}
& \mathrm{Q}_{\text {Odour }}=\mathrm{c}_{\text {Odour }} \times \dot{\mathrm{V}}_{\text {Odour }} \\
& \text { with } \dot{\mathrm{V}}_{\text {Odour }}=\frac{\mathrm{Q}_{\mathrm{CH} 4}}{\mathrm{C}_{\mathrm{CH} 4}}
\end{aligned}
$$

\section{Results and discussions}

\subsection{Fugitive methane emissions characterization}

The results of the FTIR measurements taken at the biofilter and the results from the dispersion modelling of the remote sensing data over the monitoring period are given in Table 1.

Table 1. $\mathrm{CH}_{4}$ and $\mathrm{N}_{2} \mathrm{O}$ characterization at the investigated source

\begin{tabular}{cccc}
\hline & \multicolumn{2}{c}{ FTIR } & $\begin{array}{c}\text { Remote } \\
\text { sensing }\end{array}$ \\
\cline { 2 - 4 } & $\mathrm{N}_{\mathbf{2}} \mathbf{O}$ & $\mathrm{CH}_{4}$ & $\mathrm{CH}_{4}$ \\
\hline Concentration in $\mathrm{mg} / \mathrm{m}^{\mathbf{3}}$ & 14 & 54 & \\
\hline Emission rate in $\mathrm{kg} / \mathrm{h}$ & & & 2.2 \\
\hline $\begin{array}{c}\text { Emission factor in } \mathrm{g} / \mathrm{Mg} \\
\text { input }\end{array}$ & 158 & 578 & 319 \\
\hline
\end{tabular}

The emission factors for nitrous oxide and methane, based on the input amount of biowaste on a wet weight basis, are also shown. In theory, remote sensing estimates total emission rates. That includes all collective sources as well as fugitive emission sources. However this cannot be reproduced in the results. The methane emission factors derived from the FTIR measurements are almost twice as high as the emission factors derived from the dispersion modelling of the remote sensing data. The collected exhaust air streams are actively released into the atmosphere by ventilated cooling modules after its treatment. The natural dispersion of an exhaust air plume is disturbed and remote sensing captures only parts of the emitted green house gas.

The estimated emission factors for methane are much lower than the IPCC proposed default values. Thus the impact on climate change of this plant is not severe. However the estimated emission factor for nitrous oxide is slightly lower than the default value proposed in the IPCC guideline. This could have a critical impact on climate change.

It is recognizable that the observed composting plant has major challenges with nitrous oxide emissions. It is assumed that the high nitrous oxide emissions are mainly caused by the additional treated residuals of a nearby anaerobic digestion plant. In order to minimize that problem the operating conditions of the scrubbers are changed from wet to acidic. In a subsequent measuring campaign there are already positive achievements noticeable.

\subsection{Odour emissions estimation}

In order to prove the practical applicability of the method on odour emission estimations the odour concentration in the offgas from a biofilter was measured. With an average concentration of $1200 \mathrm{OU}_{\mathrm{E}} / \mathrm{m}^{3}$ and a calculated potential volume flow from the results of the remote sensing $(2.2 \mathrm{~kg} / \mathrm{h}$ emission rate divided by the concentration of 54 $\mathrm{mg} / \mathrm{m}^{3}$ ) with about $41000 \mathrm{~m}^{3} / \mathrm{h}$ an emission rate with 49 $\mathrm{MOU}_{E} / \mathrm{h}$ was found. As previously discussed, this was about half of the expected value for only half of the plume was detected.

A more detailed evaluation of these measurements makes it possible to quantify active and passive odour sources separately. In the case under consideration, the odour load from the receiving area of a composting plant (passive source) should be determined in relation to the odour emission of the biofilter (active source). For known concentrations of odour and methane at both individual sources and the total methane load emitted by the plant, the odour load of the passive source can be calculated, as shown schematically in Figure 3.

The measured methane concentration of the biofilter of $10.2 \mathrm{mg} / \mathrm{m}^{3}$ together with the known volume flow of $100000 \mathrm{~m}^{3} / \mathrm{h}$ results in an emitted methane load of $1020 \mathrm{~g} / \mathrm{h}$ for the biofilter. The total methane load of the composting plant determined by remote sensing is $1080 \mathrm{~g} / \mathrm{h}$. Assuming that the biofilter and the receiving hall are the only potential sources, a methane load of $60 \mathrm{~g} / \mathrm{h}$ results for the receiving Area. A methane concentration of $70 \mathrm{mg} / \mathrm{m}^{3}$ was measured in the receiving hall, resulting in a potential volume flow of $850 \mathrm{~m}^{3} / \mathrm{h}$ from the passive source. If this potential volume flow is transferred to the odour emission, the results in an odorant flow rate of $520 \mathrm{OU} / \mathrm{s}$ 
(2 $200 \mathrm{OU} / \mathrm{m}^{3}$ measured odorant concentration) which is emitted through the open gate.

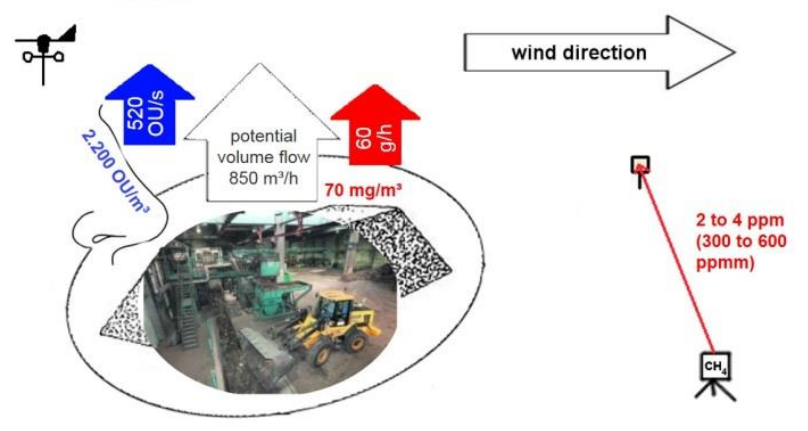

Figure 3. Odour emission estimation using Methane as a tracer

\section{Conclusion}

Since the used method is based on optical remote sensing it does not interfere with the running processes at the examined plant. So the combination of open path concentration measurements and micrometeorological dispersion modelling gives a simple and generally available method to quantify total greenhouse gas emissions at composting plants. It is possible to monitor the impact on climate change of biowaste treatment plants and to counteract when required for example at inappropriate process managements or leakage suspicions.

The proposed method is also helpful to quantify odour emissions considering methane available as a tracer to determine the emitted gas stream even from passive sources.

For the analyzed case study the fugitive methane emission rates and thus the impact on climate change are very low compared to the IPCC proposed values. However, the nitrous oxide emissions rates are critical.

\section{References}

Cadena E., Colon J., Artola A., Sanchez A. and Font X. (2009), Environmental impact of two aerobic composting technologies using life cycle assessment, The International Journal of Life Cycle Assess, 14, 401-410.

Cassendra P.C.B., Lim L.Y., Ho W.S., Lim J.S., Kleme J.J, Towprayoon S., Ho C.S. and Lee C.T. (2017), A review on the global warming potential of cleaner composting and mitigation strategies, Journal of Cleaner Production, 146, 149157.

Flesch T., Desjardins R. and Worth D. (2011), Fugitive methane emissions from an agricultural biodigester, Biomass and Bioenergy, 35, 3927-3935.

Giuliani S., Zarra T., Reiser M., Naddeo V., Kranert M. and Belgiorno V. (2012), Case studies for assessment, control and prediction of odour impact: composting plant. In: Belgiorno V., Naddeo V., Zarra T., Odour Impact Assessment Handbook, John Wiley \& Sons, Inc., 219-229, ISBN: 9781119969280.

Groth A., Maurer C., Reiser M. and Kranert M. (2015), Determination of methane emission rates on a biogas plant using data from laser absorption spectrometry, Bioresource Technology, 178, 359-361.

Hrad M., Piringer M. and Huber-Humer M. (2015), Determining methane emissions from biogas plants - Operational and meteorological aspects, Bioresource Technology, 191, 234243.

IPCC (2006), 2006 IPCC Guidelines for National Greenhouse Gas Inventories, Prepared by the National Greenhouse Gas Inventories Programme, Volume 5, Chapter 4, Eggleston H.S., Buendia L., Miwa K., Ngara T. and Tanabe K. (eds), Published: IGES, Japan.

Zarra T., Naddeo V., Belgiorno V., Reiser M. and Kranert M. (2008), Odour monitoring of small wastewater treatment plant located in sensitive environment, Water Science and Technology, 58, 89-94, ISSN: 0273-1223.

Zarra T., Naddeo V. and Belgiorno V. (2009), A novel tool for estimating the odour emissions of composting plants in air pollution management. Global Nest Journal, 11-1.4, 477-486, ISSN: 1790-7632.

Zarra T., Reiser M., Naddeo V., Belgiorno V. and Kranert M. (2014), Odour emissions characterization from wastewater treatment plants by different measurement methods, Chemical Engineering Transactions, 40, 37-42, ISSN: 19749791.

Zarra T., Naddeo V., Oliva G. and Belgiorno V. (2016), Odour emissions characterization for impact prediction in anaerobicaerobic integrated treatment plants of municipal solid waste, Chemical Engineering Transactions, 54, 91-96, ISSN: 22839216, doi: 10.3303/CET1654016.

Zhu-Barker X., Bailey S.K., Paw U.K.T., Burger M. and Horwath W.R. (2017), Greenhouse gas emissions from green waste composting windrow, Waste Management, 59, 70-79. 